\section{SOI: 1.1/TAS DOI: $10.15863 /$ TAS \\ International Scientific Journal Theoretical \& Applied Science}

p-ISSN: 2308-4944 (print) e-ISSN: 2409-0085 (online)

Year: $2016 \quad$ Issue: 4 Volume: 36

Published: $30.04 .2016 \quad \underline{\text { http://T-Science.org }}$
Kerem Seyfi Shikaliyev Azerbaijan State Oil and Industry University, professor, Doktor of chemical science, chemical-technology faculty, Azerbaijan

Maya Yadiqar Abdullayeva Azerbaijan State Oil and Industry University, Candidate of Chemical Siences, dosent, chemical -technology faculty, Azerbaijan mayaabdullayeva@hotmail.com

\title{
RESEARCH OF INFLUENCE OF MINERAL FILING ON THE PROPERTIES OF ROOD-CONSTRUCTION BITUMEN
}

\begin{abstract}
Technology production of rubber-bitumen compositions with rubber residues in form of small dispersion crumb have been developed and a properties of the received compositions have been researched. For production of asphalt concrete mixture a road bitumen and mineral powder have been modified. Covering allow in twice to decrease a level noise and vibration, to decrease a possibility formation of ice crust and to increase engagement. Thus the frost resistance and water resistance of asphalt bitumen is raise.

Key words: filing, bitumen, retrofit, polymer, adhesion, adhesive, plasticity, penetration, swellinq, conversion of polumer.

Language: Russian

Citation: Shikaliyev KS, Abdullayeva MY (2016) RESEARCH OF INFLUENCE OF MINERAL FILING ON THE PROPERTIES OF ROOD-CONSTRUCTION BITUMEN. ISJ Theoretical \& Applied Science, 04 (36): 106110.

Soi: http://s-o-i.org/1.1/TAS-04-36-15 Doi: crossef http://dx.doi.org/10.15863/TAS.2016.04.36.15

\section{ИССЛЕДОВАНИЕ ВЛИЯНИЯ МИНЕРАЛЬНОГО НАПОЛНИТЕЛЯ НА СВОЙСТВА ДОРОЖНО-} СТРОИТЕЛЬНОГО БИТУМА

Аннотация: Разработана технология получения резинобитумных композиций с резиновыми отходами в виде мелкодисперсной крошки и исследование свойства полученных композиций. Модифицирован дорожный битум и минеральный порошок для изготовления асфальтобетонной смеси. Покрытие позволяет в 2 раза снизить уровень шума и вибрацию, уменьшить возможность образования ледяной корки и повысить сцепление. Тем самым повынается морозостойкость и водостойкость асфальтобетона.

Ключевые слова: наполнители, битум, модификация, полимер, адгезия, адгезивы, набухание, пластичность, битум, переработка полимера.
\end{abstract}

Битум применяемый при выполнении оклеечной гидроизоляции, представляет собой остаток перегонки нефтепродуктов. Эта твердая на вид, черная блестящая масса, которая при воздействии длительных нагрузок сохраняет пластичность даже в условиях низких температур.

С течением времени при хранении и в эксплуатационных условиях под действием солнечного света и кислорода воздуха состав и свойства битумов изменяются: в них увеличивается относительное содержание твердых и хрупких составляющих и соответственно уменьшается количество маслянистых и смолистых фракций, в связи с чем повышается хрупкость и твердость (процесс старения).
Поэтому процесс модификации битума является весьма актуальным.

Улучшить свойства битумов возможно путем совмещения их с полимерными и минеральными наполнительными (1-3).

Обычно дорожные битумы имеют интервал пластичности, как правило, не выше 60-65C, что явно недостаточно для устройства внешних слоев покрытий в климатических условиях большинства регионов. Кроме того, у вязких дорожных битумов практически отсутствуют упругие свойства, от которых зависит устойчивость композиционных материалов, каковым является асфальтобетон, к разрушению под действием ЦИКлической нагрузки. Поэтому битумные вяжущие принципиально требуют модификации и улучшения физико-механических свойств, 
поскольку по самой своей природе не могут обеспечить необходимую стойкость асфальтобетонных покрытий дорог в условиях увеличивающихся транспортных нагрузок (2-4).

Основываясь на приведенных выше принципах, нами разработана технология получения резинобитумных композиций модификацией битума резиновыми отходами в виде мелкодисперсной крошки и исследованы свойства полученных композиций.
В качестве сырья получения резинобитумных композиций использовали: битум марки «Вак1 85/25»; резиновую крошку размером 1 мм, полученную в результате переработки изношенных автомобильных шин; в качестве сшивающего агента серу и антиоксидант неозон Д (5).

Физико-механические показатели битумов марки «Вак1 85/25»и минеральных материалов показан в таблице 1 и 2.

Таблица 1

Физико-механические показатели полученных битумов марки «Вакі 85/25», как промышленный битум.

\begin{tabular}{|l|c|c|}
\hline \multicolumn{1}{|c|}{ Показатели } & Единицы измерения & Вак1 85/25 \\
\hline Пенетрация при $25{ }^{0} \mathrm{C}$ & Мм/10 & $20-30$ \\
\hline Точка размягчения (кольцо и шар) & ${ }^{0} \mathrm{C}$ & $80-90$ \\
\hline Растяжимость при $25{ }^{0} \mathrm{C}$ & $\mathrm{cm}$ & 2,5 \\
\hline Температура вспышки & ${ }^{0} \mathrm{C}$ & 246 \\
\hline Предел прочности (по Франсу) & ${ }^{0} \mathrm{C}$ & -10 \\
\hline
\end{tabular}

Таблица 2

Основные показатели применяемых в качестве наполнителей минеральных порошков.

\begin{tabular}{|c|c|c|c|c|}
\hline № & Наименование показателей & $\begin{array}{l}\text { Шлаки } \\
\text { Гянджин- } \\
\text { ского завода } \\
\end{array}$ & $\begin{array}{c}\text { Остатки Гюздек- } \\
\text { ского каменного } \\
\text { карьера }\end{array}$ & $\begin{array}{c}\text { Пыль уноса } \\
\text { цементных } \\
\text { заводов }\end{array}$ \\
\hline 1. & $\begin{array}{l}\text { Зерновой состав, \% по массе меньше } \\
0,071 \text { мм }\end{array}$ & 70 & 40 & 70 \\
\hline 2. & Пористость, по объму & 40 & 45 & 45 \\
\hline 3. & $\begin{array}{lccc}\text { Набухание } \quad \text { образцов } & \text { из смеси } \\
\text { минерального порошка с битумом } & \\
\end{array}$ & 2,8 & 2,6 & 2,7 \\
\hline 4. & $\begin{array}{l}\text { Коэффициент водостойкости образцов из } \\
\text { смеси порошка с битумом }\end{array}$ & 0,9 & 0,81 & 0,6 \\
\hline 5. & Показатель битумоемкости, г & 200 & 100 & 100 \\
\hline 6. & $\begin{array}{l}\text { Содержание окислов щелочных металлов } \\
\left(\mathrm{H}_{2} \mathrm{O}+\mathrm{K}_{2} \mathrm{O}\right) \text {,по массе }\end{array}$ & 4 & - & 6 \\
\hline 7. & Влажность ,\% по массе & 2 & 1 & 2 \\
\hline 8. & Потери при прокаливании, \% по массе & 20 & 100 & 3 \\
\hline 9. & $\begin{array}{c}\text { Содержание водорастворимых } \\
\text { соединений , \% по массе }\end{array}$ & 1 & - & 6 \\
\hline 10. & $\begin{array}{l}\text { Содержание свободной окиси кальцияСа, } \\
\text { \% по массе }\end{array}$ & 61,1 & 56,7 & 0 \\
\hline
\end{tabular}

С целью обеспечения сцепления вводимого в асфальтобетонную смесь битума с минеральной ее частью в него следует ввести активированные продукты.

Для активации минерального порошка использованы высокомолекулярные нефтяные кислоты, полученные из Бакинской нефти (ВМНК).

ВМНК имеют ряд ценных физикохимических свойств. Несмотря на это, из ВМНК используется 20\%, поэтому использование ВМНК является весьма актуальным (5).
ВМНК вводим в минеральный порошок в процессе изготовления композиций. После введения ВМНК в минеральный порошок, выдерживали при рабочей температуре 3-4 часа.

В дальнейшем было изучено влияние ВМНК на свойства минерального порошка.

Использование в асфальтобетонных покрытиях с применением в качестве активированного минерального порошка, модифицированных по новой технологии в 3 раза выше, чем срок службы покрытий с использований активизированных минеральных порошков при тех же условиях эксплуатации. 
Покрытия позволяют в 2 раза снизить уровень шума и вибрации, уменьшить возможность образования ледяной корки, повысить сцепление, сократить тормозной путь и, кроме того, могут иметь в 1,5-2 раза меньшую толщину.

Модифицирован дорожный битум и минеральный порошок для изготовления асфальтобетонной смеси. Показано, что оптимальное количество добавки минерального порошка в битум составляет 4-5\%. Исследована технология соединения отходов резины с нефтяными битумами.

Минеральный порошок играет роль добавки, структурирующий битум в асфальтовяжущее вещество и обеспечивающее монолит зерна щебня и песка. Минеральный порошок придает асфальтобетону плотность, прочность и теплостойкость, но при избыточном содержании неактивированный минеральный порошок может привести к повышенной хрупкости и ухудшению его деформационных качеств при низких температурах(1-4).

Активизация минерального порошка повышает однородность асфальтобетонной смеси и, как следствие, степень однородности его порового пространства. Наиболее плотная упаковка частиц смеси при применении активированного минерального порошка обуславливает тенденцию к образованию замкнутых пор.

Так, для асфальтобетона $\mathrm{c}$ неактивированным минеральным порошком-17$20 \%$, что в значительной степени сказывается на повышении таких важных свойств асфальтобетона, как морозостойкость и длительная водостойкость (5-10).

В качестве минерального порошка использовано остатки Гюздекского каменного карьера (6).

С целью определения эффективности сцепления активного битума (В65) с поверхностью минерального порошка и битума проводился на лабораторном смесителе при температуре $120^{\circ} \mathrm{C}$ в течении 20 минут.

Полученные данные представлены в таблице 3 и 4.

Таблица 3

\section{Показатели активного битума с поверхностью минеральных материалов.}

\begin{tabular}{|c|c|c|}
\hline \multirow{2}{*}{ Материалы } & \multicolumn{2}{|c|}{ Степень сцепления } \\
\cline { 2 - 3 } & Без добавки & С добавкой 2-3\% \\
\hline Мингечаурский песок & 37 & 49 \\
\hline Гюздекский порошок & 51 & 60 \\
\hline
\end{tabular}

Таблица 4

Основные показатели минерального порошка.

\begin{tabular}{|c|c|c|c|}
\hline \multirow[t]{2}{*}{ Наименование показателей } & \multicolumn{3}{|c|}{ Нормы по видам порошка } \\
\hline & $\begin{array}{l}\text { Активирован- } \\
\text { ный }\end{array}$ & $\begin{array}{l}\text { Неактивирован- } \\
\text { ный }\end{array}$ & $\begin{array}{c}\text { Цементная } \\
\text { пыль }\end{array}$ \\
\hline 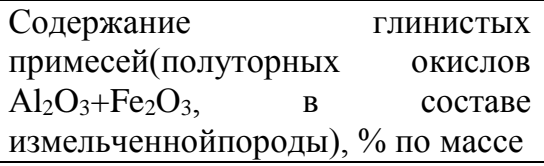 & 6,7 & 1,7 & $!, 7$ \\
\hline $\begin{array}{l}\text { Содержание частиц, \% по массе } \\
\text { мельче } 0,09 \text { мм }\end{array}$ & 75 & 40 & 60 \\
\hline Пористость ,по объему & 30 & 40 & 45 \\
\hline $\begin{array}{l}\text { Набухание смеси минерального } \\
\text { порошка с битумом, \% по объему }\end{array}$ & 2,0 & 3,0 & 3,5 \\
\hline $\begin{array}{c}\text { Показатель битумоемкости, г на } \\
100 \mathrm{~m}^{3}\end{array}$ & 60 & 70 & 100 \\
\hline Влажность , \% по массе & 0,5 & 1,0 & 1,2 \\
\hline $\begin{array}{c}\text { Водостойкость образцов из смеси } \\
\text { порошка с битумом, \% }\end{array}$ & 0,95 & 0,9 & 0,8 \\
\hline
\end{tabular}

В дальнейшем, на основе полученных минеральных порошков и активного битума (В75) была изготовлена асфальтбетонная смесь состава: (масс.Ч.-46); минеральный порошок -26; битум -10; высокомолекулярная нефтяная кислота -2 .

В ряде экспериментов активный порошок шинной резины сначала перемешивали с минеральными компонентами асфальтобетона на 
стандартном смесительном оборудовании, затем заливали смесь горячим битумом и дополнительно перемешивали всего в течении 50-100 секунд.

Несмотря на столь короткое время смешения, при этом происходит эффективное образование прочных связей между частицами резинового порошка, молекулами битума и минеральными компонентами смеси. В результате, существенно уменьшается температурный коэффициент прочности асфальтобетона, не увеличивается температура размягчения дорожного покрытия.
Например, введение 2 вес.\% активного резинового порошка в обладающий хорошими свойствами асфальт марки А приводит к увеличению его температуры размягчения в два раза, при этом возрастают морозостойкость и упругость асфальтобетона.

Как показали проведенные лабораторные исследования, такая технология введения активного резинового порошка не сопровождается деструкцией макромолекул, что обеспечивает вполне удовлетворительное эластические свойства дорожного покрытия. Введение активного порошка приводит к резкому уменьшению этих свойств(таб.5).

Результаты испытаний асфальтобетонной смеси.

Таблица 5

\begin{tabular}{|c|c|c|c|}
\hline \multirow[t]{2}{*}{ Наименование показателей } & \multicolumn{3}{|c|}{ Нормы по видам порошка } \\
\hline & $\begin{array}{c}\text { Исходный } \\
\text { битум }\end{array}$ & $\begin{array}{c}\text { активирован- } \\
\text { ный минеральный } \\
\text { порошок }\end{array}$ & ГОСТ 912827 \\
\hline 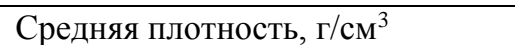 & 2,25 & 2,36 & - \\
\hline Остаточная пористость , \% по & 2,6 & 1,98 & $2,5-5,0$ \\
\hline Водонасыщение ,\%по объему & 2,0 & 1,4 & $1,5-4,0$ \\
\hline $\begin{array}{lrll}\text { Предел прочности } & \text { при } \\
\text { Па,при температуре: } & & \end{array}$ & & & \\
\hline $20^{\circ} \mathrm{C}$ & 3,0 & 3,8 & 2,0 \\
\hline $50^{\circ} \mathrm{C}$ & 1,0 & 1,9 & 0,9 \\
\hline $0^{\circ} \mathrm{C}$ & 6,0 & 7,6 & 128 \\
\hline Коэффициент водостойкости & 0,86 & 0,98 & 0,75 \\
\hline
\end{tabular}

Активизация минерального порошка повышает однородность асфальтобетонной смеси и, как следствие, степень однородности его порового пространства.

Наиболее плотная упаковка частиц смеси при применении активированного минерального порошка обуславливает тенденцию к образованию замкнутых пор. Так, для асфальтобетона с минеральным порошком -17-20\%, что в значительной степени сказывается на повышении таких важных свойств асфальтобетона, как морозостойкость.

\section{References:}

1. (2005) Kompozitsiya na osnove bitu $\neg$ ma i rezinovoy pyli. Rezinovaya promyshlennost'. Moscow, 2005, pp.131-142.

2. (1991) Posobie po stroitel'stvu asfal'tobetonnykh pokrytiy i osnovaniy avtomobil'nykh dorog i aerodro-mov. Moscow. Soyuzdor. NII, 1991, pp.182.

3. (2016) Rezinobitumnyy kompozitsionnyy material. Tekhnicheskie usloviya.TU5718-0040520977 v-01.
4. Shikhaliev KS (1982) Puti ispol'zovaniya iznoshennykh shin v Azerbaydzhanskoy SSR. Obzornaya informatsiya, ser.«Transport», Baku, zNIITI, 1982, pp.12.

5. Rudenskiy AV, Khromov AS, Mar'ev VA (2005) Otechestvennyy i zarubezhnyy opyt primeneniya rezinovoy krosh $\neg \neg \mathrm{ki}$ dlya povysheniya ka $\neg$ chestva dorozhnykh bitumov i asfal'tobetonov.M.2005, №2

6. Gasanov AA, Shykhaliev KS (2010) Issledovaniya vliyanie mineral'nogo 


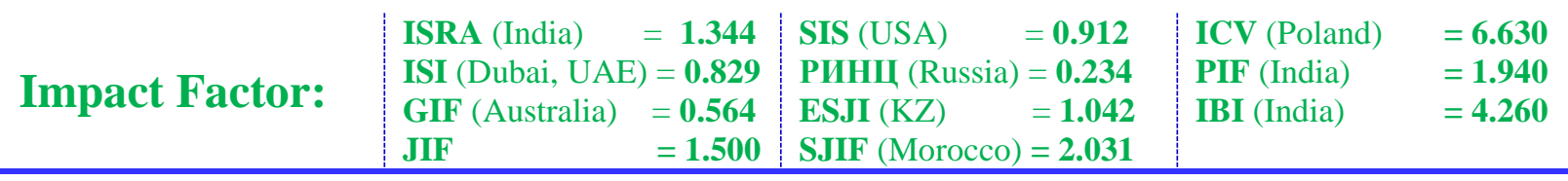

napolnitelya na svoystva dorozhno-stroitel'nogo bituma.«Ekoenergetika», V.2010, pp.111-114.

7. (2005) Patent №2266934 «Rezinosoderzhashchiy polimernyy modifikator bituma» ot 27.12.2005

8. (2002) Patent №2192400 «Bitumopeschannaya mastika dlya tonkikh sloev pokrytiy» ot 10.11.2002

9. (2005) «Rukovodstvo po stroitel'stvu dorozhnykh i aerodromnykh odezhd $\mathrm{s}$ asfal'tobetonnym pokrytiem V Azerbaydzhanskoy Respublike» (Azerbaydzhansko-Germanskoe SP«AzVIRT» TOO-Baku, 2005 .s.184)

10. Shixaliyev KS, Khalilova HK (2009) A new adsorbent for clea $\neg$ ning water surface oil and oil products. «Ekoener-qetika». 2009, №1. pp.54-57. 